\title{
Mortality among injecting drug users: a critical reappraisal
}

Martin Frischer, Michael Bloor, David Goldberg, John Clark, Stephen Green, Neil McKeganey

\begin{abstract}
Study objective-The aim was to quantify all cause mortality among injecting drug users.

Design-This was a retrospective analysis of 1989 data on injecting drug users and mortality obtained from three independent agencies: the Procurator Fiscal's Office, the General Register Office, and the Scottish HIV-test register.
\end{abstract}

Setting-Greater Glasgow, Scotland.

Subjects-Drug injectors, estimated population 9424.

Main results -81 names were found using the three sources to identify deaths. After removing duplicates, 51 deaths were found. This represented a mortality rate of $0.54 \%$ in the estimated population. Among female injectors the mortality rate was $0.85 \%$, significantly higher than the rate of $0.42 \%$ among male injectors $(95 \%$ CI for the true difference in mortality rates between female and male injectors was $0 \cdot 31 \%$ $0.55 \%$ ). Over $90 \%$ of deaths were attributed to overdose or suicide. Although AIDS caused only one death, $19 \%$ of cases $(5 / 27)$ whose HIV antibody status could be ascertained were positive. The mortality rate among HIV positive injectors $(3 \cdot 8 \%)$ was significantly higher than among HIV negative injectors $(0.49 \%)$.

Conclusions-Comprehensive coverage using three data sources revealed a far greater annual number of all cause deaths among injectors than would have been expected from previous research. The observed mortality rate was lower than in previous studies where the denominators used to calculate rates had an element of underenumeration. For the foreseeable future it is unlikely that AIDS will have much impact on mortality among injectors in Glasgow, because of the low prevalence of HIV infection among injectors in the city, and because HIV positive injectors are dying for reasons other than AIDS; rather, overdose and suicide will continue to be the main causes of death.

f Epidemiol Community Health 1993; 47: 59-63

Periodic attempts to quantify mortality among people using illicit drugs have been made in order to provide an indication of drug use in the community. However the reliability of these studies is questionable, firstly because of difficulty in obtaining information on deaths from all causes among drug users and secondly due to lack of accurate information on the appropriate base population, ie, the number of drug users. Studies in the United Kingdom have been based on highly selected groups of drug users, namely "addicts" notified to the Home Office ${ }^{12}$ or heroin users receiving treatment. ${ }^{34}$ Similarly in the USA mortality rates have been derived from follow up studies of drug users receiving treatment. ${ }^{5}$ Observed mortality rates per annum in these studies ranged from $0 \cdot 9-2 \cdot 4 \%$, with male:female ratios ranging from $3: 1$ to $6: 1$. Bucknall and Robertson $^{3}$ found that the death rate among heroin users attending an Edinburgh general practice from 1981-1985 represented an increase in the likelihood of death by a factor of 11.6 compared with the general population in Scotland, adjusted for age and sex.

With the advent of HIV infection among injecting drug users the need for accurate mortality statistics is greater than ever. The current analysis is part of a large scale study of injecting drug use in Glasgow, which has to date provided statistically reliable estimates of the number of injectors in the city ${ }^{6}$ and the HIV prevalence rate among a community wide sample of 499 injectors. ${ }^{7}$ Rather than investigating mortality among any particular group of injectors, three independent agencies with data on death among drug users resident in Glasgow extended full cooperation, enabling the most comprehensive analysis possible of deaths among injectors in Glasgow.

\section{Methods}

PERIOD OF STUDY

Given the potential size of the task of estimating the all cause mortality rate among injectors in Glasgow, the study focused on a one year period. The year 1989 was chosen because there are no reliable estimates of the number of injectors prior to that year. A secondary consideration was that one of the data sources began full scale operation in 1989.

\section{DATA SOURCES}

General Register Office (GRO)

Following the return of all death certificates in Scotland to this office, each death is coded using the International classification of diseases (ICD). Deaths are assigned a primary cause and up to three secondary causes. Where drug use is either a primary or secondary cause of death an ICD code is assigned, the exact code depending on the nature of drug involvement. Most drug related deaths are classified under the heading "Supplementary classification of external causes of injury and poisoning". In the sections on drugs giving 
rise to poisoning and other adverse effects, deaths are classified as being either accidental, suicidal, or undetermined. Other possible codes for drug related deaths are those relating to drug dependence. From the ICD codes it is not possible to ascertain whether a person was an injecting drug user, nor is it possible to determine the number of deaths of injectors who died from causes not involving drugs. Another limitation of the ICD classification relates to the wide range of drugs assigned to each code, eg, the code E950.0 corresponds to suicide involving analgesics, antipyretics and antirheumatics. Included in this category are drugs as diverse as heroin and paracetamol. In spite of these limitations, the GRO is the most comprehensive source of information on drug related deaths.

\section{Scottish $H I V$-test register}

This register was inaugurated in 1989 by the Communicable Diseases (Scotland) Unit, in conjunction with all microbiologists responsible for HIV antibody testing, and records details of all people having an HIV test in Scotland. ${ }^{8}$ (Prior to 1989 only details of HIV positive cases were available.) For each person tested, information on risk category is recorded, including whether the person is or was an injector. Information on date and circumstance of death is also recorded for tests requested by pathologists performing necropsy examinations.

\section{Procurator Fiscal's Office: Sudden Deaths Unit} (PFO)

Any sudden death of a person without a documented history of chronic illness is reported to this office which then obtains copies of the police report on the circumstances surrounding the death and the subsequent necropsy report. In view of the large number of reported sudden deaths among people aged over 40 years, the search was restricted to people aged 40 and under, among whom sudden death is less prevalent and injecting drug use more common. From examination of the police and necropsy reports it was possible to distinguish between deaths of injecting and non-injecting drug users. Only the former, including both those dying directly from drug intoxication and those dying for other reasons (not necessarily related to drug use), were included in the analysis.

\section{PROCEDURE}

To estimate the mortality rate of injectors in Glasgow each data source was asked to supply limited identifier information to enable cross matching of cases among the different agencies. Assurance was given that strict anonymity and confidentiality would be maintained. Four types of identifiers were sought: (1) date of birth, (2) sex, (3) initials, (4) first part of postcode. At the

Table I Sources of information on deaths in Glasgow, 1989.

\begin{tabular}{|c|c|c|c|c|c|c|c|c|}
\hline \multirow[b]{2}{*}{ Source } & \multirow[b]{2}{*}{$n$} & \multicolumn{2}{|c|}{ Male } & \multicolumn{2}{|c|}{ Female } & \multicolumn{2}{|c|}{ Age (years) } & \multirow[b]{2}{*}{$H I V+$} \\
\hline & & $n$ & $\%$ & $n$ & $\%$ & Mean & Range & \\
\hline $\begin{array}{l}\text { Procurator Fiscal's Office } \\
\text { General Register Office } \\
\text { HIV register } \\
\text { Unique cases }\end{array}$ & $\begin{array}{l}24 \\
32 \\
25 \\
51\end{array}$ & $\begin{array}{l}13 \\
16 \\
17 \\
29\end{array}$ & $\begin{array}{l}(54) \\
(50) \\
(68) \\
(57)\end{array}$ & $\begin{array}{r}11 \\
16 \\
8 \\
22\end{array}$ & $\begin{array}{r}(467) \\
(50) \\
(32) \\
(43)\end{array}$ & $\begin{array}{l}27 \cdot 1 \\
27 \cdot 4 \\
27 \cdot 7 \\
27 \cdot 2\end{array}$ & $\begin{array}{l}21-35 \\
17-39 \\
17-43 \\
17-43\end{array}$ & $\begin{array}{l}4 \\
\text { na } \\
3 \\
5\end{array}$ \\
\hline
\end{tabular}

na $=$ not available.
PFO, a manual search was made through the necropsy and police reports, looking for any indication that the person was an injecting drug user, irrespective of the cause of death. Details of any relevant cases were recorded. Data from the other two sources were obtained in the form of computer printouts.

ANAL YSIS

Planned comparisons of mortality rates for male injectors $v$ female injectors, HIV positive injectors $v$ HIV negative injectors, male injectors $v$ male general population, and female injectors $v$ female general population were made using the test recommended by Fleiss ${ }^{9}$ for assessing differences in proportions from two populations. The results of this test are described by the $z^{2}$ statistic which is distributed as $\chi^{2}$ with one degree of freedom.

\section{Results}

RELATIONSHIP BETWEEN SOURCES

Information was obtained on a total of 94 deaths; 24 from the PFO, 25 from the HIV-register, and 45 from the GRO. Cross matching of these cases revealed a high proportion of the GRO group (28/45) who did not appear in the other sources. Of t'.1e 28 cases, $13(46 \%)$ were aged over 40 years a:d therefore could not overlap with the PFO data which contained only cases aged 40 or under. While this group of cases may have included the occasional injector, it seems prudent to err on the side of caution and exclude these 13 cases from the analysis since they were probably straightforward suicidal drug overdoses. On the other hand the probability that the remaining 15 cases aged under 40 years were injectors is supported by the fact that $96 \%$ of "problem" drug users seen by treatment agencies in Glasgow in 1989 were aged 40 or under, ${ }^{10}$ and that among this group of drug users over $90 \%$ were injectors. Furthermore it has also been reported that in addition to heroin, other drugs, particularly temazepam and buprenorphine, are widely injected in Glasgow. ${ }^{11}$ In view of these indicators it seems reasonable to suggest that, unless there is evidence to the contrary, young people dying of drug overdoses in 1989 were likely to have been injectors. The figure shows the results of the cross matching analysis of

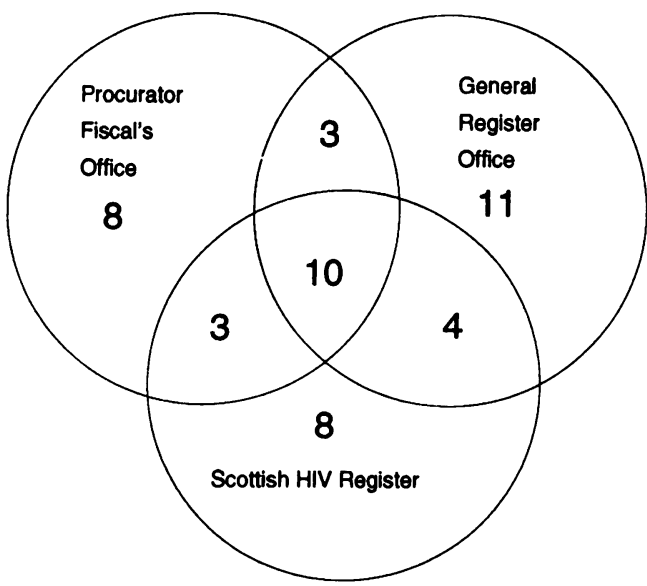

Figure Recorded deaths among injecting drug users in Glasgow during 1989. 
the 81 cases included in the study. Ten cases were recorded by all three sources, 10 by two sources, and the remaining 31 were recorded by one source. Thus the 81 cases recorded by the three sources represent 51 individuals.

\section{AGE AND SEX COMPOSITION OF SAMPLES}

There were no significant differences between the samples in terms of age $(F=0.07$, between groups $\mathrm{df}=2$, within groups $\mathrm{df}=48, \mathrm{p}=0.75$ ) or sex $\left(\chi^{2}=1.28, \mathrm{df}=2, \mathrm{p}=0.52\right)$. The mean age of injectors who died in 1989 was 27 years and $43 \%$ were female (table I).

COMPARISON OF MORTALITY RATES BETWEEN INJECTORS AND THE GENERAL POPULATION

In order to estimate the mortality rate among injectors it is necessary to relate the number of deaths (numerator) to the number of injectors (denominator). The latter information is available from a recently completed study. The methodology, described in detail elsewhere, ${ }^{6}$ involved using $\log$-linear analysis to estimate the number of injectors, unknown to drug treatment agencies, the police, or the Scottish HIV-test register in Glasgow for 1989. The resultant median number of estimated injectors broken down by age and gender is shown in the first column of table II. While the top age band ( $35-55$ years) is not ideal for the current analysis, in view of the fact that deaths over 40 years of age were not analysed for two of the three sources, it was not possible to obtain more detailed estimates with satisfactory reliability for those aged 35 and over. Thus it should be noted that the mortality rates for people aged 35 and over may be underestimates.

With 29 deaths, the mortality rate for male injectors was $0.42 \%$ compared to $0.28 \%$ among the general population $\left(z^{2}=4 \cdot 2, p<0.05\right)$. Examination of age bands showed significant differences for those aged 20-24 years $\left(z^{2}=41 \cdot 1\right.$, $\mathrm{p}<0.01), 25-29$ years $\left(\mathrm{z}^{2}=41 \cdot 1, \mathrm{p}<0.01\right)$, and 30-34 years $\left(z^{2}=3 \cdot 84, p<0 \cdot 05\right)$. The differences for those aged 15-19 years $\left(z^{2}=1 \cdot 76, p=0 \cdot 20\right)$ and those aged $35-55$ years $\left(z^{2}=0.05, p=0.99\right)$ were not significant.

Although there were 22 deaths among female injectors, the estimated female injector population in 1989 was less than half that of males and

Table II Comparison of mortality rates: injectors (IDUs): Glasgow 1989 and the general population: Scotland, 1989. Means and totals in bold type.

\begin{tabular}{|c|c|c|c|c|c|}
\hline \multirow[b]{2}{*}{$\begin{array}{l}\text { Age range } \\
\text { (years) }\end{array}$} & \multirow[b]{2}{*}{$\begin{array}{l}\text { Number } \\
\text { of IDUs }\end{array}$} & \multirow[b]{2}{*}{$\begin{array}{l}\text { Number of } \\
\text { deaths among } \\
\text { IDUs }\end{array}$} & \multicolumn{2}{|c|}{ Mortality rate } & \multirow[b]{2}{*}{$\begin{array}{l}\text { Mortality ratio } \\
\text { IDUs: general } \\
\text { population }\end{array}$} \\
\hline & & & $I D U s$ & $\begin{array}{l}\text { General } \\
\text { population }\end{array}$ & \\
\hline \multicolumn{6}{|c|}{ Males } \\
\hline $\begin{array}{l}15-19 \\
20-24 \\
25-29 \\
30-34 \\
35-55 \\
15-55\end{array}$ & $\begin{array}{r}634 \\
2316 \\
1596 \\
1014 \\
1276 \\
\Sigma=6836\end{array}$ & $\begin{array}{r}2 \\
8 \\
12 \\
4 \\
3 \\
\Sigma=29\end{array}$ & $\begin{array}{c}0.31 \\
0.35 \\
0.75 \\
0.39 \\
0.23 \\
\bar{\chi}=0.42\end{array}$ & $\begin{array}{r}0.08 \\
0.11 \\
0.13 \\
0.13 \\
0.58 \\
\bar{\chi}=0.28\end{array}$ & $\begin{array}{r}3.9 \\
3.2 \\
5.8 \\
3.0 \\
0.4 \\
\bar{\chi}=1.5\end{array}$ \\
\hline $\begin{array}{l}15-19 \\
20-24 \\
25-29 \\
30-34 \\
35-55 \\
15-55\end{array}$ & $\begin{array}{r}469 \\
685 \\
992 \\
229 \\
213 \\
\Sigma=2588\end{array}$ & $\begin{array}{r}1 \\
4 \\
9 \\
5 \\
3 \\
\Sigma=22\end{array}$ & $\begin{array}{rr} & \\
0.21 & \\
0.58 \\
0.91 \\
2.18 \\
1.41 \\
\bar{\chi}=\mathbf{0 . 8 5}\end{array}$ & $\begin{array}{r}0.03 \\
0.05 \\
0.05 \\
0.07 \\
0.36 \\
\bar{\chi}=0.21\end{array}$ & $\begin{array}{r}7.0 \\
11 \cdot 6 \\
18 \cdot 2 \\
31 \cdot 2 \\
3.9 \\
\bar{\chi}=4.0\end{array}$ \\
\hline \multicolumn{6}{|c|}{ Males + females } \\
\hline
\end{tabular}

consequently the mortality rate for females $(0.85 \%)$ was significantly higher $\left(z^{2}=5 \cdot 68\right.$, $p<0.05)$ than for males. The $95 \%$ confidence interval for the true difference in mortality rates between female and male injectors was $0.31 \%$ $0.55 \%$. Compared to the general population, female injectors had significantly higher mortality rates $\left(20-24\right.$ years: $z^{2}=28 \cdot 1, p<0.01 ; 25-29$ years: $z^{2}=11.3, p<0.01 ; 30-34$ years: $z^{2}=62.6$, $\mathrm{p}<0.01 ; 35-55$ years: $\left.\mathrm{z}^{2}=3.9, \mathrm{p}<0.05\right)$, with the exception of those aged $15-19$ years $\left(z^{2}=0.08\right.$, $\mathrm{p}=0.99$ ).

\section{CAUSES OF DEATH}

In 32 out of 51 cases the primary cause was ascertained from the GRO data. As table IIIA shows, all 32 were attributed to the adverse effects of drugs. For 17 of the 19 deaths not recorded by the GRO, which in most cases meant injectors not dying primarily from a drug overdose, details on cause of death were obtained from the necropsy report at the PFO. As table IIIB shows, there were various causes of death among this group, none of which were directly attributed to a drug overdose with the exception of one case where the primary cause of death was given as hypoxic brain damage due to a drug overdose, although the drug was not specified. Finally no information on cause of death was available for two cases recorded on the HIV-test register.

Table III Primary cause of death among drug users in Glasgow during 1989.

$\frac{\text { Male }}{n o_{o}} \frac{\text { Female }}{n o_{o}^{o}} \frac{\text { All }}{n o_{o}}$

A. Primary cause of death as defined by the GRO

Drug dependence

Opiate (accidental)

piate (suicide)

Barbiturate (suicide)

Other drugs (suicide)

Opiate (undetermined)

Sedative (undetermined)

Tranquilliser (undetermined)
Other drugs (undetermined)

Subtotal

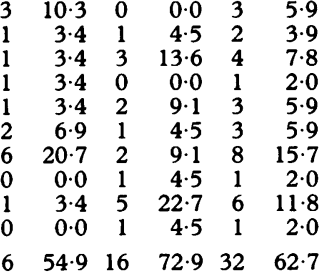

B. Cause of death in additional cases as noted

on necropsy report

Road traffic accident

Bacterial endocartitis

Myocardial fibrosis

Alcohol inging

Hepatitis

Hepatitis
Epileptiform seizure
Inhalation of gastric contents

Inhalation of gastric contents
Overdose (no specified drug)

Overdose (no specified drug

Multip

Unknown ${ }^{a}$

Subtotal

$\begin{array}{rr}0.0 & 1 \\ 3.4 & 0 \\ 3.4 & 0 \\ 3.4 & 1 \\ 13.8 & 0 \\ 3.4 & 0 \\ 3.4 & 0 \\ 0.0 & 1 \\ 3.4 & 0 \\ 3.4 & 2 \\ 0.0 & 1 \\ 6.9 & 0\end{array}$

$\begin{array}{lll}4 \cdot 5 & 1 & 2 \cdot 0 \\ 0 \cdot 0 & 1 & 2 \cdot 0\end{array}$

Total

GRO = General Register Office.

The categories of drugs shown above are those used in the International classification of diseases (9th revision). Cause of death may be attributed to one of three categories: accidental poisoning, suicidal poisoning, and poisoning undetermined whether accidental or intentional.

$a^{a}$ These cases were obtained from the HIV register and there were no details on cause of death.

Using all available information from the GRO and the PFO it is possible to summarise the causes of death using the categories shown in table IV. Almost $90 \%$ of recorded deaths were due to overdose $(47 \cdot 1 \%)$ or suicide $(35 \cdot 3 \%)$. 
Table IV Main categories of death among drug users in Glasgow during 1989.

\begin{tabular}{|c|c|c|c|c|c|c|}
\hline & \multicolumn{2}{|c|}{ Male } & \multicolumn{2}{|c|}{ Female } & \multicolumn{2}{|l|}{ All } \\
\hline & $n$ & ${ }^{o} o$ & $n$ & ${ }^{\circ}$ & $n$ & ${ }^{\circ}{ }_{0}$ \\
\hline $\begin{array}{l}\text { Overdose } \\
\text { Suicide } \\
\text { AIDS } \\
\text { Other medical causes } \\
\text { Accidental } \\
\text { Unknown }\end{array}$ & $\begin{array}{r}13 \\
10 \\
0 \\
4 \\
0 \\
2\end{array}$ & $\begin{array}{c}44 \cdot 8 \\
34 \cdot 5 \\
0 \\
13 \cdot 8 \\
0 \\
6 \cdot 9\end{array}$ & $\begin{array}{r}11 \\
8 \\
1 \\
1 \\
1 \\
0\end{array}$ & $\begin{array}{r}50 \cdot 0 \\
36 \cdot 4 \\
4 \cdot 5 \\
4 \cdot 5 \\
4 \cdot 5 \\
0\end{array}$ & $\begin{array}{r}24 \\
18 \\
1 \\
5 \\
1 \\
2\end{array}$ & $\begin{array}{r}47 \cdot 1 \\
35 \cdot 3 \\
2 \cdot 0 \\
9 \cdot 8 \\
2 \cdot 0 \\
3 \cdot 9\end{array}$ \\
\hline Total & 29 & 100 & 22 & 100 & 51 & 100 \\
\hline
\end{tabular}

HIV ANTIBODY STATUS

Information on HIV antibody status was obtained for all deaths reported from the HIV-test register. As the figure shows, of the 25 cases obtained from this source, 10 were also recorded by both the GRO and PFO, four by the GRO only, and three by the PFO only. Of the remaining 26 cases it was only possible to determine the status of a further two cases from the necropsy reports. Of the 27 cases of known HIV status, five (19\%) were HIV antibody positive and $22(81 \%)$ were HIV antibody negative. Table $\mathrm{V}$ shows that three out of the five positive cases were recorded in the HIV-test register. Two cases were known positives and one was found to be positive only after post mortem testing. The remaining two cases were said to have AIDS in their necropsy reports and were therefore assumed to be HIV antibody positive. Table $\mathrm{V}$ also shows that four out of the five cases were female. Given the estimate of 9424 current injectors in Glasgow, with $133 \mathrm{HIV}$ positive, ${ }^{7}$ then the proportion of HIV positive injectors dying in 1989 was $3.8 \%$ (5/133), significantly higher $\left(\mathrm{z}^{2}=21 \cdot 1, \mathrm{p}<0.01\right)$ than for HIV negative injectors $(0.5 \% ; 46 / 9291)$.

\section{Discussion}

The 1989 mortality of $0.54 \%$ among injectors in Glasgow is considerably lower than that found in any of the previous studies cited in the introduction. However the numerator used to calculate this rate represents 51 deaths in Glasgow during 1989; by comparison, for the whole of the United Kingdom, there were 69 deaths among addicts notified to the Home Office between 1956 and $1966^{1}$ and 65 deaths between 1967 and $1981 .^{2}$

Examination of mortality rates per se may be misleading unless both numerator and denominator are kept firmly in mind. Although mortality may change for many reasons, for example type and purity of drugs injected, experience of users, etc, it is likely that the Home Office figures seriously overestimate the true annual mortality among injectors, primarily because of the highly selected nature of reported addicts and the underreporting of deaths among injectors because of the low numbers of registered addicts. The number of addicts notified from Greater Glasgow in 1989 was 142 , which clearly does not reflect the scale of injecting in the city, given that well over 1000 individuals received treatment for drug abuse

Table $V$ Causes of death and other information on HIV positive injectors.

\begin{tabular}{|c|c|c|}
\hline Cause of death & Information on HIV & Gender \\
\hline $\begin{array}{l}\text { Opiate (accidental) } \\
\text { Opiate (accidental) } \\
\text { Tranquillisers (undetermined) } \\
\text { AIDS } \\
\text { Inhalation of gastric contents }{ }^{a}\end{array}$ & $\begin{array}{l}\text { Known positive } \\
\text { Positive following necropsy } \\
\text { Not recorded in HIV register } \\
\text { Known positive } \\
\text { Not recorded in HIV register }\end{array}$ & $\begin{array}{l}\mathrm{F} \\
\mathrm{M} \\
\mathrm{F} \\
\mathrm{F} \\
\mathrm{F}\end{array}$ \\
\hline
\end{tabular}

${ }^{a}$ These cases were said to have AIDS in their necropsy reports, although AIDS was not mentioned on the death certificates. during the year in question. ${ }^{10}$ Although the level of undernotification may not be so extreme in England, it must be recognised that mortality among notified addicts may not be indicative of mortality among the wider population of injectors.

Another major difference between the current and previous studies was the higher mortality among female injectors $(0.85 \%)$ compared to male injectors $(0.42 \%)$ in Glasgow. Previous studies, while reporting a preponderance of male deaths (eg, Bewley and co-workers ${ }^{1}$ report 58 males and 11 females in the United Kingdom between 1956-66), have not examined gender differences in detail. In the present study comparison of injector to general population mortality rates shows that whereas male injectors were, on average, 1.5 times more likely to die than their peers, females were, on average, four times more likely. There are no obvious reasons to explain this gender differential in terms of cause of death. The proportion of deaths caused by suicide, for example, was similar for males and females. While the high female injector/general population mortality ratio is partly a consequence of the lower death rates among females compared to males in the general population, these findings highlight the risk of death for female injectors and suggest that this group may require particular targeting by those involved in providing drug treatment services.

The third major finding in the current study concerns HIV antibody status. Of the 27 injectors whose HIV status was known, five $(19 \%)$ were HIV positive. Even if there were no further positive cases among the 24 whose status was unknown, the prevalence of HIV among this sample would still be far higher than the rate of $1.4 \%(95 \%$ confidence interval: $0.6 \%-2.9 \%)$ observed in a recent study of 499 Glasgow resident injectors recruited from 28 sites, in and out of drug treatment, around the city. ${ }^{7}$ While the gender breakdown of the 499 cases $(71 \%$ male, $29 \%$ female) mirrors the 1989 injector prevalence estimates shown in table II, all seven cases who were found to be HIV antibody positive were male. On this basis we would expect that the vast majority of deaths among HIV injectors for all causes would be among males. This was not the case, however, as females accounted for $80 \%$ (4/5) of the known positive cases among deaths in 1989 . While the small number of cases precludes statistical analysis of gender differences it seems plausible to hypothesise that, for reasons as yet unknown, female injectors with HIV are more likely to die from all causes.

Of the four female cases, one died from AIDS, two from overdoses (one accidental, one undetermined) and one died from inhalation of gastric contents. Two of the necropsy reports on these cases (accidental overdose and inhalation of gastric contents) stated that the individuals had AIDS. While this information does not permit any inference as to whether the disease was a contributory factor in their death, the proportion of HIV positive injectors dying in 1989 was significantly higher than among HIV negative injectors.

The relatively low number of HIV positive cases in Glasgow associated with injecting drug 
use means that AIDS is unlikely to become one of the major causes of death among the city's injectors for the foreseeable future. On the strength of the data presented here, suicide and overdose will probably continue to be the main causes of death in Glasgow; it is noteworthy that no deaths in 1989 were caused by homicide. The only other study with sufficient numbers to make meaningful comparisons in terms of cause of death found that $10 \%$ of non-therapeutic heroin addicts who died in the United Kingdom between 1956 and 1966 died as a result of violent incidents. ${ }^{1}$

In Edinburgh, where many more HIV positive injectors have been reported ( 558 by December $1989^{12}$ ), the proportion of AIDS related deaths will probably rise more dramatically, although because of the long incubation period for development of AIDS from HIV infection, this will probably not occur until the mid 1990s at the earliest, since most seroconversions are thought to have occurred after 1983 . To date 17 injectors have died of AIDS in Edinburgh. Thus Edinburgh has not observed the level of AIDS mortality reported by, for example, Bologna, where 151 injectors have died of AIDS up to 1990 and where it is thought that AIDS is now responsible for half of all deaths among injectors. ${ }^{13}$

Finally, it should be noted that the ICD codes currently used to classify drug related deaths are not precise enough to discriminate injectors from non-injectors. Since death certificates give precise information on the type of drug involved in overdoses we would recommend that the next revision of the ICD should feature an expanded coding framework, so that each drug is assigned a separate code. This enhancement of the ICD would not only enable a much greater degree of certitude in identifying injectors but also facilitate examination of other important issues, for example, to what extent is buprenorphine, widely injected in Glasgow, associated with overdose, in comparison to heroin?

In conclusion, this study has shown that, while the mortality rate among injectors may be lower than was previously thought, the large number of drug related deaths has probably not been fully appreciated. In addition to the causes of death seen in the pre-HIV era, AIDS must now be added. Although not yet a major cause of death compared to overdose and suicide, AIDS deaths will increase in the next few years, albeit with significant regional variations. While it may be too late to prevent the deaths of those already infected with HIV, the number of young people who will lose their lives in the coming years will increase unless drug injecting and associated transmission of the HIV virus through sharing of injecting equipment declines in Britain's urban areas.

The authors are grateful to staff at the General Register Office, the Procurator Fiscal's Office, and the Communicable Diseases (Scotland) Unit. Particular thanks are due to Elizabeth Munro and William Smyth without whom the analysis could not have been conducted. The research reported here was supported by grant number SPG8913894 from the Medical Research Council.

1 Bewley TH, Ben-Arie O, Pierce J. Morbidity and mortality Bewley TH, Ben-Arie O, Pierce J. Morbidity and mortality from heroin dependence. 1: Survey of her

2 Ghodse AH, Sheehan M, Taylor C, Edwards G. Death of drug addicts in the United Kingdom, 1967-1981. BMF 1985; 290: 425-8.

3 Bucknall AB, Robertson JR. Death of heroin users in general practice population. $\mathcal{F} R$ Coll Gen Pract 1986, 36 $120-2$.

4 Skidmore CA, Robertson JR, Savage G. Mortality and increasing drug use in Edinburgh: implications for the HIV epidemic. Scott Med F 1990; 35: 100-2.

5 George JW, Lehman W, Simpson D. Addict death rates during a four-year posttreatment follow-up. Am 7 Public Health 1982; 72: 703-8.

6 Frischer M, Bloor M, Finlay A, et al. A new method of estimating prevalence of injecting drug use in an urban population: results from a Scottish city. Int $\mathcal{\exists}$ Epidemiol population: results

7 Haw S, Frischer M, Covell R, et al. HIV infection and risk behaviour among injecting drug users in Glasgow. Answer behaviour among injecting drug users in Glasgow. Answer
(AIDS News Supplement, CDS Weekly Report) 1991; (AIDS News

8 Goldberg D, Emslie J, Smyth W, Allardice G, Reid D. Surveillance of voluntary diagnostic HIV-testing in Scotland. Abstract No. MC 3255 in VII International Conference on AIDS abstract book. Rome: Instituto Superiore, 1991

9 Fleiss J. Statistical methods for rates and proportions. New York: John Wiley, 1976

10 Frischer $M$. Estimated prevalence of injecting drug use in Glasgow. Br F Addict 1992; 87: 235-43.

11 Barnard M, McKeganey N. Adolescents, sex and injecting drug use: risks for HIV infection. Aids Care 1990; 103-16.

12 Anonymous. Human immunodeficiency virus (HIV) infection. Scotland: quarterly report to 31 December 1989. Answer (AIDS News Supplement, CDS Weekly Report) 1990; A132: $90 / 02$.

13 Goedert J, Pizza G, Gritti F, et al. Cancer, AIDS and other mortality rates among drug users in Bologna. Abstract No. THC 47 in VII International Conference on AIDS abstract book. Rome: Instituto Superiore, 1991. 